\title{
A Sequential Analysis of Private and Social Speech in Children's Dyadic Communication
}

\author{
Dolors Girbau \\ Jaume I University
}

\begin{abstract}
The purpose of this study was to perform a sequential analysis of private and social speech in children's dyadic communication. To investigate the communication patterns, a category system was applied to the communication of 64 paired third ( $M=8$ years and 8 months) and fifth ( $M=10$ years and 8 months) graders, while playing with a Lego-set (construction material). The results revealed that: (a) at both grades, when one child addresses the other child about the task, it is highly probable that the latter will address the first child immediately afterwards and will adapt to task-related semantic content; (b) at both grades, children's private speech about the task stops them from communicating a task-related production to their partner immediately afterwards; (c) at third grade, task-relevant private speech favors the prolongation of the break in interpersonal communication and the use of inner speech by both children; and (d) at fifth grade, children are more able to distinguish private speech from social speech than at third grade.
\end{abstract}

Key words: private speech, silence, social speech, dyads, sequential analysis, age-differences

\begin{abstract}
El objetivo de este estudio fue realizar un análisis secuencial del habla privada y social en la comunicación diádica infantil. Para investigar los patrones comunicativos, se aplicó un sistema de categorias a la comunicación de 64 sujetos de tercer ( $M=8$ años y 8 meses) y quinto ( $M=10$ años y 8 meses) curso, emparejados mientras jugaban con el juego Lego (un material de construcción). Los resultados permitieron concluir lo siguiente: (a) en ambos cursos, cuando un sujeto se dirige al otro haciendo alguna alusión a la tarea, es altamente probable que este último se dirija al primer interlocutor inmediatamente después y, a la vez, se adapte al citado contenido semántico relacionado con la tarea; (b) en ambos cursos, el habla privada sobre la tarea les inhibe de comunicarse con el compañero sobre la tarea inmediatamente después; (c) en el tercer curso, el habla privada relacionada con la tarea favorece la prolongación de la ruptura de la comunicación interpersonal y el uso de habla interna por parte de ambos sujetos; y (d) los alumnos de quinto curso son más capaces de distinguir el habła privada del habla social que los de tercero.

Palabras clave: habla privada, silencio, habla social, diadas, análisis secuencial, diferencias por edad
\end{abstract}

This study is from a more extensive project, which was funded by two grants from the Institut de Sociolinguística Catalana (Generalitat de Catalunya), and by another grant from the Divisió de Ciències de la Salut - University of Barcelona.

I am grateful for the valuable advice of Prof. H. Boada. I also thank Prof. V. Quera, Prof. M.T. Anguera for their methodological teaching, and Prof. J. C. Oliver for reviewing the English.

Correspondence concerning this article should be addressed to Dolors Girbau, Departamento de Psicología Básica, Clínica y Psicobiología. Universidad Jaume I. Campus Borriol. 12080 Castellón de la Plana (Spain). E-mail: girbau@psb.uji.es 
Private speech has too frequently been studied in isolation from social speech, so that research about private speech in children's dyadic communication is almost nonexistent. Authors have preferred to analyze private speech only in children who were alone or, at most, with a minimally responsive adult (see Diaz \& Berk, 1992; and Fuson, 1979, for a review). According to Fuson (1979), the presence of another person creates the problem of separating social speech from private speech. Despite this obstacle, it would be interesting to know how private speech produced in a children's dyadic setting affects this communicative process, and to verify aspects such as the progressive differentiation between private and social speech, which was partly studied by Vygotsky (1934/1987).

Historically, the terms private and social speech have been labeled and conceptualized in different ways (see Girbau, 1996, for a critical review). On the basis of the works of Flavell (1964/1966) and Piaget (1923/1968), private speech may be defined as speech that is neither addressed nor adapted to a partner, as distinct from social speech, which is addressed to a partner.

Another area that has attracted little attention is the study of private speech after the age of 8 (Diaz \& Berk, 1992; Fuson, 1979). This is very probably because of the impact of the theories of Piaget (1923/1968) and Vygotsky (1934/1987), which established the disappearance of egocentric speech around the age of 7 . In this regard, Vygotsky's contribution is of particular note in clarifying that this egocentric speech is transformed to inner speech. According to Piaget (1923/1968), egocentric speech is characterized mainly by nonadaptation to the interlocutor's point of view, and by talking about oneself. Vygotsky (1934/1987) distinguished between overt verbal thinking (egocentric speech) and soundless inner speech, and stated that the study of egocentric speech is the method of choice for investigating inner speech. Therefore, influence of age on private speech from a naturalistic approach has been much more studied to date than the effect of other variables, for example, sex (Diaz \& Berk, 1992; Fuson, 1979). After the age of 7, external private speech was used by all 8 - and 10year-old children within a social context (Girbau, in press).

The multiple methodological difficulties involved in this topic are well known. One of them is the kind of statistical data analysis used in research of private speech. There is a clear preference in these studies for experimental data analyses over observational analyses. This is an obstacle because the former type of analysis, although of interest to study the significant differences in the frequency of speech categories at different ages, does not examine the interactions involved in the communication process. Observational data analysis, however, makes such an examination possible by means of sequential analysis (Quera \& Bakeman, 2000). This methodology detects sequential patterns (behaviors that are significantly related within a sequence), which can be either activating or inhibiting. Thus, the probability for a certain behavior (antecedent) to activate or inhibit another behavior (consequent) occurring immediately afterwards may be determined (Girbau, 1999). Surprisingly, sequential analysis of private and social speech in children's dyadic communication seems to have been neglected. Therefore, the sequences of private and / or social speech subcategories in which children communicate (either intra- or interlocutorily), that is, children's communicative sequential patterns, are currently not known.

The present study analyzes data sequentially by means of a category system. This system takes into account the distinction between speech dimensions, focusing on two (form and content) out of the three dimensions of form, content, and function (Diaz, 1986, 1992; Meichenbaum \& Goodman, 1979). Silence was included as an analysis category to study inner speech (Vygotsky, 1934/1987), which also eliminates blank observation points (behaviors that otherwise would not be either observed or analyzed) and thus makes up an exhaustive category system. This category does not seem to have been analyzed in this field from this theoretical and methodological approach. With respect to the duration of silence, from a referential perspective, Krauss and colleagues (Bricker, Garlock, Krauss, \& McMahon, 1977; Krauss, 1987; Krauss \& Bricker, 1967) concluded that a delay of 1.8 seconds in the back-channel response a short utterance produced by one participant in a conversation while the other is talking (Ward \& Tsukahara, 2000) - is sufficient to disrupt the speaker's ability to refer efficiently to the referent or to extend and / or repeat the produced message.

The aim of the present study is to determine children's sequential patterns (of activation and inhibition) for the subcategories of private and social speech, in a dyadic situation, which does not seem to have been reported to date. Particularly, the progressive differentiation between social and private speech -including inner speech-- with age will be investigated beyond the age of 7 , by comparing the communicative patterns of third-grade and fifth-grade dyads. It was hypothesized that the older children would be more able to distinguish private speech from social speech than would the younger ones. A second hypothesis was that, at both grades, the content of the interpersonal communicative pattern would be significantly task-focused.

\section{Method}

\section{Participants}

The group consisted of 64 children, 32 from third grade and 32 from fifth grade, from a middle-class school in Barcelona. There were 32 girls (14 third graders and 18 fifth graders) and 32 boys ( 18 third graders and 14 fifth graders). The mean ages were 8 years and 8 months ( $S D=3$ months, ranging from $8 ; 2$ to $9 ; 2)$ and 10 years and 8 months $(S D=$ 
3 months, ranging from $10 ; 2$ to $11 ; 2$ ), respectively. An intelligence test (Cattell \& Cattell, 1973) was administered collectively in each of the four class groups ( 2 classrooms for each grade) to 97 pupils (49 third-grade students and 48 fifth-grade students). Subjects with most extreme scores in that test of "g" factor (who scored within the range 73-89 and 124-134) and with any kind of important school troubles (according to the school psychologist) were excluded. The selected group of 64 participants had an average IQ of 108 $(S D=7.90$, ranging from 92 to 122 ). The 64 children were paired, matching both members of each dyad as much as possible in terms of: (a) grade (16 third-grade dyads and 16 fifth-grade dyads); (b) age; (c) intelligence (the mean difference in IQ between two members of a dyad was $M=$ 3.94 and $S D=2.69$ for third graders, and $M=2.75$ and $S D$ $=2.27$ for fifth graders, respectively); (d) sex (15 male dyads, 15 female dyads, and 2 mixed dyads); and (e) class group (30 dyads from the same class, and 2 dyads whose members were from different classes, but who were friends).

\section{Material}

A Lego-set within an open transparent container was displayed on a working table, at which both children sat down. A Lego-set, which is construction material made up of small pieces of plastic that can be assembled to build houses, etc., is a natural task (which the children had performed before), according to Fuson's (1979) classification of tasks as natural and artificial.

\section{Procedure}

Participants were called, two at a time, to a school-room that was equipped with a video camera (connected to a microphone) and a tape recorder. The observer (author) instructed the children as follows: "Now you may play for a while and, when I come back, I want you to tell me whether you enjoyed the game, and what you have built." Then the observer left the room. This moment marked the start of the transcription, which lasted 8 minutes per dyad. The first child to speak after the door was closed was called interlocutor $A$, and the other child was interlocutor $B$. This situation therefore belongs to the naturalistic approach, in which both participants are considered equal at the communicative level, both being interlocutors (because each one is simultaneously a potential speaker and listener). The videotaped sessions (also audiotaped to ensure recording quality) were transcribed and categorized by the author. The transcription was done according to the unit of categorization concept as it is defined in the category system described below. Hence, it includes the totality of: (a) externalized verbal productions by means of words or sounds; (b) clearly communicative gestures that substitute a verbalization that would be appropriate; and (c) silences.

\section{Category System}

The category system displayed in Table 1 was applied to the transcript. Because the literature on private speech does not provide any one universally agreed-upon criterion to unitize the stream of utterances or to categorize units, in addition to the new features of this category system, various viewpoints were integrated (e.g., Berk \& Spuhl, 1995; Kohlberg, Yaeger, \& Hjertholm, 1968; Manning, White, \& Daugherty, 1994; Meichenbaum \& Goodman, 1979; Piaget, 1923/1968).

Categorization unit. The categorization unit was defined as: (a) external verbal production by means of words or sounds (including shouting, audible non-overlapping laughter, feigned weeping, whistling, and sighing); or (b) clearly communicative gestures in substitution of a verbalization that would correspond there (only considered as such when the gesture responded to a request for information or for action, being transcribed sequentially at the moment the gesture started); or (c) silence (a pause of 2 or more seconds, during which neither of the two previously mentioned units appeared).

As to the criteria for segmentation into units, at least one of the following conditions had to be fulfilled: (a) a

Table 1

Category System

\begin{tabular}{llll}
\hline & Form & Content \\
\hline Social Speech & Audible & Task-irrelevant & {$[$ IrAuSo] } \\
& & Task-relevant & {$[$ ReAuSo] } \\
& & Task-irrelevant & {$[$ IrAuPr $]$} \\
Private Speech & Audible & Task-relevant & {$[\operatorname{ReAuPr}]$}
\end{tabular}


change of turn -the shift of interlocutors always signaled a new unit; (b) a category change - when, within the same turn, two or more categories were recognized (according to the operative definitions below), each of them was coded. If, upon one interlocutor's turn ending, there was silence (of 2 or more seconds), this was also coded, thus separating it from previous and subsequent utterances.

Operationalization of the categories. Categories were operationalized as (a) social speech, (b) private speech, or (c) untranscribable. Within the categories, according to their form, social speech could only be audible, whereas private speech could be audible, inaudible, or silent. Both social and private speech could be task-relevant or task-irrelevant.

Social speech (So). This was defined as a categorization unit (in terms of external verbal production or clearly communicative gestures as operationalized above) addressed to the play-partner (interlocutor). At least one of the following conditions had to be fulfilled:

1. Eye-contact simultaneously or immediately preceding or subsequent to a piece of information provided to the partner.

2. The verb is in second person singular (you) or first person plural (we), addressing the partner.

3. The interlocutor requests information or action (e.g., "look") from the partner.

4. The interlocutor initiates a new communicative exchange with the partner (e.g., giving the partner information).

5. The interlocutor repeats or reformulates a message addressed to the partner immediately or very soon after having sent a similar message.

6. The interlocutor requests the partner's attention by means of vocatives (e.g., "eh!") or physical contact. The request must be accompanied by at least one of the other conditions, except when the interlocutor also shows an object to the partner, and the partner looks at it.

7. The interlocutor answers the partner's request for information or action.

8. The interlocutor completes a sentence initiated previously by the partner.

9. A categorization unit directly related to the information (private or social) provided by the partner immediately before or after, or very shortly before that categorization unit.

10. It is usually a contribution to the conversation (although it may be just "yes," "no," or a laugh). It includes linguistic exchanges such as the interlocutory ritual (repetition of verbalizations by both speakers, which maintains a foreseeable regular thythm), or interlocutory singing (partners alternately produce parts of the same song).

Audible ( $A u$ ). Production volume (high, normal, or low) makes it intelligible to a listener, and it can be transcribed. Task-irrelevant ( $I r)$. Speech outside the given task construction play, neither directly related nor referred to the task, although it may be preceded by a task-relevant category that causes this irrelevant category (which is no longer a direct effect of the task). It includes allusion to (a) aspects of the environment (e.g., the weather) or the observer, unrelated to the task; (b) personal physical or psychological states that are not a direct consequence of the task (e.g., hunger); (c) personal experiences unrelated to the task.

Task-relevant (Re). The content of speech refers to the task. It includes: (a) any mention of task materials or characteristics; (b) productions concerning problems, plans, procedures, and results of the task (e.g., counting the pieces); (c) allusion to task-related previous personal experiences or to the observer with regard to the task (e.g., possible performance time); (d) task-relevant fantasy; (e) productions that are a direct effect of the task (e.g., "good!," "mm") and that may be a rhythmic accompaniment to task actions.

Private speech (Pr). This categorization unit is not addressed or adapted to the listener, but to the speaker himor herself. Sometimes, private speech is displayed in the reduction of voice volume; if volume was very low, speech was subcoded as inaudible. At other times, it is accompanied by great attention to the task. It includes: (a) speech addressed at an object, a phenomenon of nature, or an absent person (real or imaginary). The interlocutor addresses the object or person as if it were a human interlocutor (with a second-person verb), ignoring the play-partner. There is therefore no eye-contact with the partner, either simultaneously or immediately before or after such speech; (b) an answer to a request for information formulated by the same participant in such a way that neither the request nor the answer initiates a new communicative exchange. Between the two utterances there could only be one other category at most, or two if one of them was silence. Request and answer were coded as private speech. Thus, if one of the utterances initiated a new communicative exchange (social speech) and the other did not (private), there would be two different categories.

Like social speech, private speech can also be categorized as audible, task-irrelevant, and task-relevant, which were defined above. It can also be inaudible and silent.

Inaudible (Inau). This subcategory refers to production in a very low voice, almost inaudible, and also made evident by lip movements. It follows the voice volume criterion: The voice was not loud enough to attribute any semantic content to the verbalization and was unintelligible to a very near listener.

Silent (Sil). A pause of 2 or more seconds during which none of the other categories appeared, so there was no external verbal production or inaudible lip movements and no clearly communicative gesture (as defined above).

Untranscribable (Unt). Unintelligible production due to recording conditions, defective audible vocalization, or whispering into partner's ear. If immediately before or after this untranscribable production, there was a unit that was intelligible but not categorizable due to unawareness of the content of the untranscribable production, this intelligible unit was also included in this category. 
According to the above categorization system, social speech (always audible) could be categorized as taskirrelevant (IrAuSo) or task-relevant (ReAuSo). On the other hand, private speech could be categorized as inaudible (InauPr), silent (SilPr), audible and task-irrelevant (lrAuPr), or audible and task-relevant (ReAuPr). For example: «If you find one like this, give it to me.» [ReAuSo]; «La, la, la, la, la, la.» [rAuPr].

\section{Reliability}

For the segmentation in units, the inter-rater agreement index (Pearson's coefficient) between two judges was $r=.91$, $p<.001$, based on 4 dyads (496 tums). For the categorization, from 1586 units (of these 4 dyads), the inter-rater concordance index (Cohen's Kappa) was $\kappa=.80, p<.01$, which was excellent, as it was higher than .75 (Fleiss, 1981).

\section{Results}

In order to reduce the length of this section, speech categories will be referred to by their abbreviations. First, the descriptive statistics of the categories by grades and sex will be presented and, subsequently, the results of the sequential analysis.
Percentages and Variability of the Category Units

A total of 7170 categorized units was obtained, from which the percentage distribution of the seven categories was calculated, as shown in Table 2. Due to the very low incidence of the untranscribable category and because of its traits, this category was excluded from the remaining calculations (variability of frequencies and some aspects of sequential analyses). It should also be noted that every child in the study engaged both in inner and external private speech.

\section{Sequential Analyses}

Data were analyzed from an interactive perspective, relying on a maximum of 32 sessions or dyads (the number of pairs depended on the grouping of data). According to Bakeman and Quera (1995b), the current data are nonrepeatable event sequential data (ESD), as only the order of coded events was recorded and no category could be immediately repeated. Six of the categories (excluding silence) were recoded, adding the letters $A$ or $B$ according to the interlocutor speaking (i.e., ReAuSo-A, ReAuSo-B, etc.). This allowed distinguishing whether a significant sequence of two categories was intralocutory (produced by the same subject) or interlocutory (one by each child).

Table 2

Means, Standard Deviations, and Percentages of Categories by Dyadic Grade, Sex, and Total Grouping

\begin{tabular}{|c|c|c|c|c|c|c|c|c|}
\hline & & IrAuSo & ReAuSo & IrAuPr & $\mathrm{ReAuPr}$ & InauPr & SilPr & Unt \\
\hline \multirow[t]{3}{*}{$3 \mathrm{rd}^{a}$} & $M$ & 32.38 & 89.81 & 12.50 & 26.06 & 12.63 & 27.44 & \\
\hline & $S D$ & 29.21 & 31.03 & 11.42 & 12.89 & 8.00 & 9.54 & \\
\hline & $\%$ & 15.83 & 43.93 & 6.11 & 12.75 & 6.18 & 13.42 & 1.77 \\
\hline \multirow[t]{3}{*}{$5 \mathrm{th}^{\mathrm{a}}$} & $M$ & 17.50 & 130.69 & 12.75 & 33.75 & 22.94 & 22.75 & \\
\hline & $S D$ & 24.99 & 38.49 & 13.36 & 14.85 & 9.10 & 13.01 & \\
\hline & $\%$ & 7.18 & 53.63 & 5.23 & 13.85 & 9.41 & 9.34 & 1.36 \\
\hline \multirow[t]{3}{*}{ Male $^{b}$} & $M$ & 21.47 & 114.93 & 12.60 & 27.33 & 18.80 & 24.93 & \\
\hline & $S D$ & 25.73 & 33.29 & 11.66 & 9.98 & 9.70 & 10.55 & \\
\hline & $\%$ & 9.57 & 51.25 & 5.62 & 12.19 & 8.38 & 11.12 & 1.87 \\
\hline \multirow[t]{3}{*}{ Female $^{\mathrm{b}}$} & $M$ & 28.67 & 109.20 & 13.73 & 33.60 & 18.00 & 23.53 & \\
\hline & $S D$ & 31.92 & 48.19 & 13.55 & 16.93 & 10.22 & 12.30 & \\
\hline & $\%$ & 12.50 & 47.62 & 5.99 & 14.65 & 7.85 & 10.26 & 1.13 \\
\hline \multirow[t]{3}{*}{ Mixed $^{\mathfrak{c}}$} & $M$ & 23.00 & 83.00 & 4.50 & 21.50 & 8.50 & 38.00 & \\
\hline & $S D$ & 0.00 & 12.73 & 3.54 & 20.51 & 9.19 & 5.66 & \\
\hline & $\%$ & 12.57 & 45.35 & 2.46 & 11.75 & 4.64 & 20.76 & 2.46 \\
\hline \multirow[t]{3}{*}{ Total $^{d}$} & $M$ & 24.94 & 110.25 & 12.63 & 29.91 & 17.78 & 25.09 & \\
\hline & $S D$ & 27.79 & 40.17 & 12.23 & 14.23 & 9.93 & 11.47 & \\
\hline & $\%$ & 11.13 & 49.20 & 5.63 & 13.35 & 7.94 & 11.20 & 1.55 \\
\hline
\end{tabular}

${ }^{\mathrm{a}} n=16$ dyads. ${ }^{\mathrm{b}} n=15$ dyads. ${ }^{\mathrm{c}} n=2$ dyads. ${ }^{\mathrm{d}} n=32$ dyads.

Note. IrAuSo = Task-irrelevant audible social speech; ReAuSo = Task-relevant audible social speech; IrAuPr = Task-irrelevant audible private speech; $\operatorname{ReAuPr}=$ Task-relevant audible private speech; InauPr = Inaudible private specch; $\operatorname{SilPr}=\operatorname{Silent}$ private speech; Unt = Untranscribable. 
Specifically, the lag method (Sackett, 1979) was used, with its subsequent improvements (Bakeman \& Quera, 1995a, 1995b; Sackett, 1987). Lag I was analyzed according to the following procedure (Bakeman \& Quera, 1995a). The observed frequencies of lag 1 were arranged in a 2 dimensional contingency table, in which rows represented given behaviors (the first behavior to occur) and columns represented target behaviors (occurring immediately after given behaviors). The six categories (excluding the untranscribable one) were considered possible given and target behaviors, but all seven categories were retained in the data as a whole. Chi-square was calculated with the SDIS \& GSEQ computer program (Bakeman \& Quera, 1995a). Significant chi-square values indicate that given and target behaviors were related sequentially. When this occurred, adjusted residuals ( $z$ ) were computed to determine the sequential patterns of activation $(z \geq 1.96)$ and inhibition ( $z \leq-1.96$ ) of the target behavior (Haberman, 1978). A pattern of activation indicates that when a given behavior occurs (a certain speech category), it is significantly likely that, immediately afterwards, a target behavior will occur (another specific speech category). On the other hand, a pattern of inhibition means that when a particular given behavior occurs, it is significantly likely that, immediately afterwards, a specific target behavior will not occur. Thus, the likelihood that a specific category (antecedent) will activate or inhibit a particular category (consequent) immediately afterwards will be revealed.

This section presents the sequential analyses that were performed in the total group, and in the subgroups by dyadic grade and sex. The sequential patterns with a symmetrical relation (regardless of the interlocutor) will be described below, leaving the comments about the asymmetric pattems (whose significance depends on the interlocutor) for the discussion.

Total grouping. For the 32 dyads, $\chi^{2}(89)=7526.57, p$ $=.0000$, based on an observed Lag 1 total frequency of 6914. The application conditions (Siegel, 1956) for chisquare were fulfilled: For tables with more than 1 degree of freedom, less than $20 \%$ of cells may have expected frequencies of less than 5 , and none of less than 1 . Thus, the expected frequency of less than 5 was $1.8 \%$, and there were none of less than 1 . The sequential pattems are shown in Table 3: In each pattern (e.g., [ReAuSo-A]-[ReAuSo$B]$ ), the first behavior is the given behavior (e.g., [ReAuSoA]), and the following one is the target behavior (e.g., [ReAuSo-B]).

As shown in Table 3, ReAuSo speech was inhibited by silence [SiPr]; intralocutory ReAuSo speech was inhibited by ReAuPr, InauPr, IrAuSo, and IrAuPr; interlocutory ReAuSo speech was also inhibited by the latter two categories. ReAuSo speech activated the same category when the utterances were produced by different subjects. Lastly, silence [SilPr] was inhibited by ReAuSo speech and activated by ReAuPr.
Grouping by Grade. The application conditions (Siegel, 1956) for both chi-squares were again met. The expected frequencies of less than 5 were $14.5 \%$ for third grade and $18.2 \%$ for fifth grade, there were none of less than 1 . For the 16 dyads of third grade, $\chi^{2}(89)=3613.10, p=.0000$ (with an observed Lag 1 total frequency of 3137 ), whereas for the 16 dyads of fifth grade, $\chi^{2}(89)=3749.48, p=.0000$ (with 3777 as observed Lag I total frequency). As both chisquares were significant, the adjusted residuals $(z)$ were obtained; the significant ones are reported in Table 3.

As can be seen, some sequential patterns were found to be common to both grades. Intralocutory ReAuSo specch was inhibited by ReAuPr and IrAuSo, as was interlocutory ReAuSo speech by the latter category (IrAuSo). Moreover, interlocutory ReAuSo speech activated ReAuSo speech also in both grades. Some symmetrical patterns were present only in one grade. Particularly, ReAuPr speech activated silence [SilPr] only in third grade. Only in the fifth graders, intralocutory ReAuSo speech was inhibited by InauPr and IrAuPr; and interlocutory ReAuSo speech was also inhibited by the latter (IrAuPr). ReAuSo was also inhibited by silence [SilPr] in the fifth-grade students.

Grouping by Sex. Two of the three sequential analyses could not be calculated because Siegel's (1956) conditions were not fulfilled. These were the 15 male dyads, in which $21.8 \%$ of expected frequencies were less than 5 (none of less than $I$ ), and, obviously, the 2 mixed dyads (with $80 \%$ and $53.6 \%$ of less than 5 and of less than $l$, respectively). In the 15 female dyads, $\chi^{2}(89)=3809.45, p=.0000$ (with an observed Lag 1 total frequency of 3220 ). Its expected frequencies of less than 5 were $10.9 \%$ (none of less than I). As shown in Table 3, intralocutory ReAuSo speech was inhibited by ReAuPr, InauPr, and IrAuSo; interlocutory ReAuSo speech was also inhibited by IrAuSo and by IrAuPr. Moreover, ReAuSo speech activated interlocutory ReAuSo speech and inhibited silence [SilPr], which, in turn, was activated by $\operatorname{ReAuPr}$.

\section{Discussion}

Sequential analyses indicate that some patterns are displayed constantly, namely, in the whole group, in the thitd grade, the fifth grade, and in the female sex. In the conditions described above, the present data reveal that ReAuSo (taskrelevant audible social speech) leads to interlocutory ReAuSo, that is, ReAuSo in the partner. Furthermore, IrAuSo (taskirrelevant audible social speech) does not lead either to interlocutory or intralocutory ReAuSo. Thus, when a member of the dyad addresses the other member about the task, it is highly probable that the latter will reply in kind, immediately afterwards, and adapting to the semantic content. Moreover, just after social productions that are unrelated to the task are made, social task-relevant productions are unlikely; these task-irrelevant productions clearly distract participants from 
Table 3

Activating and Inhibiting Sequential Patterns by Total Grouping, Grade, and Fenale Sex: Adjusted Residuals

\begin{tabular}{|c|c|c|c|c|}
\hline Sequential patterns & $\begin{array}{c}\text { Total Grouping } \\
n=32 \text { dyads }\end{array}$ & $\begin{array}{l}3^{\text {rd }} \text { Graders } \\
n=16 \text { dyads }\end{array}$ & $\begin{array}{l}5^{\text {th }} \text { Graders } \\
n=16 \text { dyads }\end{array}$ & $\begin{array}{c}\text { Females } \\
n=15 \text { dyads }\end{array}$ \\
\hline \multicolumn{5}{|l|}{ ACTIVATING PATTERNS } \\
\hline [ReAuSo-A]-[ReAuSo-B] & $24.31^{* * * *}$ & $17.82^{* * * *}$ & $16.29^{* * * * *}$ & $18.10^{* * * *}$ \\
\hline$[\operatorname{Re} A u S o-B]-[\operatorname{ReAuSo}-\mathrm{A}]$ & $22,09^{* * * *}$ & $16.59^{* * * *}$ & $14.44^{* * * *}$ & $17.16^{* * * *}$ \\
\hline [IrAuPr-B]-[SilPr] & $2.76^{* *}$ & $4.74^{* * * *}$ & $\mathrm{~ns}$ & $3.23^{\mathrm{k*k}}$ \\
\hline$[\operatorname{ReAuPr}-\mathrm{A}]-[\mathrm{SilPr}]$ & $9.19^{* * * *}$ & $5.54^{* * * * *}$ & ns & $7.37^{* * * *}$ \\
\hline$[$ ReAuPr-B]-[SilPr] & $3.81^{* * * *}$ & $2.68^{* *}$ & ns & $2.95^{* *}$ \\
\hline \multicolumn{5}{|l|}{ INHIBITING PATTERNS } \\
\hline [IrAuSo-A]-[ ReAuSo-B] & $-9.80^{* * * *}$ & $-7.39^{* * * *}$ & $-6.02^{* * * *}$ & $-7.23^{* * * *}$ \\
\hline [IrAuSo-B]-[ReAuSo-A] & $-10.21^{* * * *}$ & $-8.19^{* * * *}$ & $-5.61^{* * * *}$ & $-7.41^{* * * * *}$ \\
\hline [IrAuSo-A]-[ReAuSo-A] & $-11.34^{* * * *}$ & $-8.95^{* * * *}$ & $-6.52^{* * * *}$ & $-7.97^{* * * * *}$ \\
\hline [IrAuSo-B]-[ReAuSo-B] & $-11.03^{* * * * *}$ & $-8.81^{* * * *}$ & $-6,23^{* * * *}$ & $-8.01^{* * * *}$ \\
\hline [ReAuSo-A]-[SilPr] & $-3.47^{* * *}$ & ns & ns & $-2.22^{*}$ \\
\hline [ReAuSo-B]-[SilPr] & $-4.43^{* * * *}$ & $-2.00^{*}$ & ns & $-3.15^{* *}$ \\
\hline [IrAuPr-A]-[ReAuSo-B] & $-2.00^{*}$ & ns & $-3.24^{* *}$ & $-3.35^{* * *}$ \\
\hline [IrAuPr-B]-[ReAuSo-A] & $-4.16^{* * * *}$ & $-2.07^{*}$ & $-3.72^{* * *}$ & $-4.34^{* * * *}$ \\
\hline [IrAuPr-A]-[ReAuSo-A] & $-3.23^{* *}$ & ns & $-3.45^{* * *}$ & ns \\
\hline [IrAuPr-B]-[ReAuSo-B] & $-5.16^{* * * *}$ & $-2.64^{* *}$ & $-4.52^{* * * *}$ & $-4.35^{* * * *}$ \\
\hline [ReAuPr-A]-[ReAuSo-B] & $-4.77^{* * * *}$ & ns & $-4.70^{* * * *}$ & $-3.28^{* *}$ \\
\hline$[\operatorname{ReAuPr}-\mathrm{A}]-\left[\operatorname{Re} A \mathrm{uSo}_{\mathrm{S}} \mathrm{A}\right]$ & $-8.77^{* * * *}$ & $-5.24^{* * * *}$ & $-7.10^{* * * *}$ & $-6.90^{* * * *}$ \\
\hline [ReAuPr-B]-[ReAuSo-B] & $-8.06^{* * * *}$ & $-4.76^{* * * *}$ & $-6.54^{* * * *}$ & $-6.01^{* * * *}$ \\
\hline [InauPr-A]-[ReAuSo-A] & $-5.50^{* * * *}$ & ns & $-5.91^{* * * *}$ & $-4.12^{* * * *}$ \\
\hline [InauPr-B]-[ReAuSo-B] & $-5.13^{* * * *}$ & $-3.00^{* *}$ & $-4.35^{* * * *}$ & $-3.01^{* *}$ \\
\hline [SilPr]-[ReAuSo-A] & $-3.39^{* * *}$ & ns & $-2.42^{*}$ & ns \\
\hline$[$ SilPr $] \cdot[\operatorname{ReAuSO}-\mathrm{B}]$ & $-6.32^{* * * *}$ & $-4.33^{* * * *}$ & $-4.21^{* * * *}$ & $-3.50^{* * *}$ \\
\hline
\end{tabular}

Note. IrAuSo = Task-irrelevant audible social speech; ReAuSo = Task-relevant audible social speech; IrAuPr = Task-irrelevant audible private speech; $\operatorname{ReAuPr}=$ Task-relevant audible private speech; InauPr = Inaudible private speech; SilPr $=$ Silent private speech; Unt = Untranscribable.

${ }^{*} p<.05 .{ }^{* *} p<.01{ }^{* * *} p<.001{ }^{* * * *} p<.0001$.

the assigned task. The pattern of interpersonal communication at both grades is characterized by a clearly task-focused content. This shows that, at third and fifth grades ( 8 and 10 years, respectively), children already have considerable ability to adapt communicatively to their interlocutor, and at the same time, to the request to focus on the task.

Also for all groupings, task-relevant audible private speech [ReAuPr] does not lead to intralocutory task-relevant audible social speech [ReAuSo]. Children's absorption with the task stops them from communicating task-related productions to their partner immediately after their own private speech. This inhibiting pattern emphasizes the speakers' intention of addressing themselves and not their partner. Task-relevant private productions are thus neither a preamble, nor do they aim at preparing utterances addressed to the partner with similar content for immediate production.

In the third-grade dyads only, and for both interlocutors, task-relevant audible private speech [ReAuPr] leads to silence
[SilPr]. Thus, only at this age level, task-relevant private speech favors the prolongation of the break in the interpersonal communication and the use of inner speech by both subjects. In fifth graders, task-relevant audible social speech [ReAuSo] is inhibited by all the remaining subcategories, intralocutory and/or interlocutory (not only by IrAuSo and ReAuPr, as in almost all the other groupings, but also by private task-irrelevant-audible -IrAuPr-, inaudible -InauPr-, and silent -SilPr- speech). Older children may be more able to distinguish private from social speech, realizing that private speech is not part of interpersonal communication and involves no intention of communicating with the partner. This could complement the Vygotskyan progressive differentiation (with age) between egocentric speech and communicative speech. He established this differentiation. based mainly on the function and structure of speech (Vygotsky, 1934/1987), but not at an interactive level. However, contrary to Vygotsky, external private speech was 
found after the age of 7 ; Vygotsky had set the age of complete transformation of egocentric speech into inner speech at 7, as did Piaget (1923/1968), although there were conceptual differences between these two authors.

The last aspect is the presence of asymmetric patterns, which differ depending on which interlocutors (A or B) are involved -for example, patterns revealed when the sequence is $A-B$ but not when the sequence is B-A. Eight of these asymmetric patterns involve the inhibition of task-relevant social speech by interlocutor $B$ after silence or private speech. Therefore, it seems that interlocutor B is less likely to start a task-relevant conversation. This is hardly surprising, as it indicates that the child who speaks second is less dominant. This additional information is revealed because of the sensitivity of sequential analysis, which casts doubt on the so-called peer interactions. Those asymmetries might also be due to the influence of other variables, besides the most frequently controlled ones (Girbau, 2002).

More research is therefore needed to better understand how the various types of private and social speech may be sequentially related as a function of multiple variables. The progressive distinction between private speech and social speech, including the role of silence, after the age of 7 deserves to be studied in depth. Both types of speech are present in a dyadic communication and have their own importance as cognitive processes with different degrees of complexity.

\section{References}

Bakeman, R., \& Quera, V. (1995a). Analyzing interaction: Sequential analysis with SDIS and GSEQ. New York: Cambridge University Press.

Bakeman, R., \& Quera, V. (1995b). Log-linear approaches to lagsequential analysis when consecutive codes may and cannot repeat. Psychological Bulletin, 118, 272-284.

Berk, L.E., \& Spuhl, S.T. (1995). Maternal interaction, private speech and task performance in preschool children. Early Childhood Research Quarterly, 10, 145-169.

Bricker, P.D., Garlock, C.M., Krauss, R.M., \& McMahon, L.E. (1977). The role of audible and visible back-channel responses in interpersonal communication. Journal of Personality and Social Psychology, 9, 295-300.

Cattell, R.B., \& Cattell, A.K.S. (1973). Measuring intelligence with The Culture Fair Tests (4th ed.). Champaign, IL: Institute for Personality and Ability Testing. [Spanish version: Tests de factor "g», Escalas 2 y 3. (1986). Madrid: TEA.]

Diaz, R.M. (1986). Issues in the empirical study of private speech: A response to Frawley and Lantolf's commentary. Developmental Psychology, 22, 709-711.

Diaz, R.M. (1992). Methodological concerns in the study of private speech. In R.M. Diaz \& L.E. Berk (Eds.), Private speech: From social interaction to self-regulation (pp. 55-81). Hillsdale, NJ: Erlbaurn.
Diaz, R.M., \& Berk, L.E. (1992). Private speech: From social interaction to self-regularion. Hillsdale, NJ: Erlbaum.

Flavell, J.H. (1966). Le langage privé. Bulletin de Psychologie, 19, 698-701. [Originally presented at the Annual Meeting of the American Speech and Hearing Association, San Francisco, November 1964.]

Fleiss, J.L. (1981). Statistical methods for rates and proportions. New York: Wiley.

Fuson, K.C. (1979). The development of self-regulating aspects of speech: A review. In G. Zivin (Ed.), The development of selfregulation through private speech (pp. 135-217). New York: Wiley.

Girbau, D. (1996). Private and social speech in communication: Terminology and distinctive traits. Joumal of Psycholinguistic Research, 25, 507-513.

Girbau, D. (1999). El estudio de la comunicación mediante la metodología observacional. In M.T. Anguera (Ed.), Observación de la conducta interactiva en contextos naturales: Aplicaciones (pp. 243-268). Barcelona: Edicions de la Universitat de Barcelona.

Girbau, D. (2002). Psicología de la comunicación. Barcelona: Ariel.

Girbau, D. (in press). Private and social speech in children's dyadic communication in naturalistic context. Anuario de Psicología, 33.

Haberman (1978). Analysis of qualitative data (Vol. 1). New York: Acadernic Press.

Kohlberg, L., Yaeger, J., \& Hjertholm, E. (1968). Private speech: Four studies and a review of theories. Child Development, 39, 691-736.

Krauss, R.M. (1987). The role of the listener: Addressee influences on message formulation. Journal of Language and Social Psychology, 6, 81-98.

Krauss, R.M., \& Bricker, P.D. (1967). Effects of transmission delay and access delay on the efficiency of verbal communication. Journal of the Acoustical Society, 41, 286-92.

Manning, B.H., White, C.S., \& Daugherty, M. (1994). Young children's private speech as a precursor to metacognitive strategy use during task engagement. Discourse Processes, 17, $191-211$

Meichenbaum, D., \& Goodman, S. (1979). Clinical use of private speech and critical questions about its study in natural settings. In $\mathrm{G}$. Zivin (Ed.), The development of self-regulation through privale speech (pp. 325-360). New York: Wiley.

Piaget, J. (1968). Le langage et la pensée chez l'enfant. Etudes sur la logique de l'enfant [The language and thought of the child] ( $7^{\text {th }}$ ed.). Neuchâtel, Switzerland: Delachaux et Niestle. (Original work published 1923.)

Quera, V., \& Bakeman, R. (2000). Quantification strategies in behavioral observation research, In $\mathrm{T}$. Thompson, D. Felce, \& F. Symons (Eds.), Behavioral observation: Technology and applications in developmental disabilities (pp. 297-315). Baltimore, MD: Brookes Publishing.

Sackett, G. P. (1979). The lag sequential analysis of contingency and cyclicity in behavioral interaction research. In J.D. Osofsky 
(Ed.), Handbook of infant development ( $1^{\text {st }}$ ed., pp. 623-649). New York: Wiley.

Sackett, G.P. (1987). Analysis of sequential social interaction data: Some issues, recent developments, and a causal inference model. In J.D. Osofsky (Ed.), Handbook of infant developnent ( $2^{\text {nd }}$ ed., pp. 855-878). New York: Wiley.

Siege!, S. (1956). Nonparametric statistics for the behavioral sciences. Tokyo: McGraw-Hill.

Vygotsky, L.S. (1987). The collected works of L.S. Vygotsky: Vol. 1. Problems of General Psychology. Including the Volume
Thinking and Speech. (R.W. Rieber \& A.S. Carton, Eds.; N. Minjck, Trans.). New York: Plenum Press. (Original work published 1934.)

Ward, N., \& Tsukahara, W. (2000). Prosodic features which cue back-channel responses in English and Japanese. Journal of Pragmatics, 32, 1177-1207.

Received January 2, 2002 Revision received September 2, 2002 Accepted September 6, 2002 